\title{
Phenotypic Resistance to Amphotericin B in Candida albicans: the Role of Reduction
}

\author{
By E. F. GALE, ALISON M. JOHNSON, D. KERRIDGE AND \\ ELIZABETH A. MILES \\ Sub-Department of Chemical Microbiology, Biochemistry Department, \\ University of Cambridge, Cambridge CB2 $1 Q W$
}

(Received 9 June 1978)

The development of resistance to amphotericin B methyl ester (AME), measured in terms of the amount ( $\mu \mathrm{g} \mathrm{AME} \mathrm{ml}{ }^{-1}=$ s.r.c.) of the antibiotic required to induce a standard rate of release of $\mathrm{K}^{+}$from suspensions of washed organisms, has been followed in Candida albicans in starved cultures under controlled conditions of aeration, $\mathrm{pH}$, stirring and temperature for periods up to $120 \mathrm{~h}$, and the amino acid content of the pool and the carbohydrate content of the organisms have been determined. The soluble glucan fraction of the cells decreased during the first $24 \mathrm{~h}$ starvation but no significant changes were observed in other carbohydrate or lipid fractions. At $\mathrm{pH} 3$, the glutamate content of the pool decreased rapidly during the starvation period but other amino acids showed a general pattern of increase during the first 24 to $72 \mathrm{~h}$ and decrease during the later stages of starvation. Increasing the glutamate content of the pool by growth in media supplemented with sodium glutamate delayed the onset of resistance, and, in all experiments, high resistance did not develop until the glutamate content of the pool had fallen below $10 \mathrm{nmol}$ (mg dry wt organisms) ${ }^{-1}$. There was a highly significant correlation between the level of resistance and (i) the glutamate concentration in the pool and (ii) the rate of disappearance of glutamate from the pool.

Treatment of starved organisms with $N$-ethylmaleimide (NEM) increased the resistance, the increase ranging from 10-fold for cultures starved for $24 \mathrm{~h}$ to 2 -fold or less for cultures starved for $120 \mathrm{~h}$. The resistance of NEM-treated organisms increased with the time of starvation. Treatment of organisms with $\beta$-mercaptoethanol (ESH) decreased resistance; for organisms after 24 to $96 \mathrm{~h}$ starvation, possessing moderate resistance (s.r.c. 15 to 20), treatment with ESH reduced this resistance to a value approximating to that of growing organisms (s.r.c. $0 \cdot 1$ ). In organisms starved for longer periods and with higher resistance, the effect of ESH was smaller and the level of ESH-insensitive resistance increased rapidly with time. Resistance thus developed in two stages; first, a stage where reduction of some components of the cell decreased resistance and, later, a stage of high resistance unaffected by reduction. Changes, similar in quality but smaller in quantity, were found in the development of resistance in organisms grown and starved at $\mathrm{pH} 7$.

The activities of glutamate: NAD ${ }^{+}$oxidoreductase (EC 1.4.1.2) and glutamate: NADP ${ }^{+}$ oxidoreductase (EC 1.4.1.3) have been estimated in extracts from organisms during growth and starvation; the NAD-linked enzyme activity remained relatively unchanged during the starvation period of $96 \mathrm{~h}$ while the NADP-linked enzyme activity decreased markedly during the first $24 \mathrm{~h}$ starvation. Estimation of the degree of reduction of the cellular NAD during the starvation period showed that AME resistance rose as the ratio of cellular $\mathrm{NADH} / \mathrm{NAD}^{+}$decreased.

It is suggested that the first stage of phenotypic resistance can be attributed to a reducible factor in the cell wall, and that the amount of this factor increases during starvation but that the developed resistance is determined by the degree of reduction of this factor. The evidence is not inconsistent with glutamate in the pool acting as a major source of reducing potential. 


\section{INTRODUCTION}

The sensitivity of Candida albicans to polyene antibiotics can be assessed by monitoring the leakage of potassium ions from the organisms under standard conditions (Gale, 1974). Organisms in the exponential phase of growth are highly sensitive to amphotericin B methyl ester (AME), 0.1 $\mu \mathrm{g} \mathrm{AME} \mathrm{ml}^{-1}$ (s.r.c. = standard release concentration) inducing a leakage rate of $1 \mathrm{nmol} \mathrm{K} \mathrm{Kin}^{-1}$ (mg dry wt organisms) ${ }^{-1}$ above that in controls without AME within $8 \mathrm{~min}$. However, the sensitivity decreases as the culture passes into the stationary phase so that organisms from the late-stationary phase may have a resistance two to three orders of magnitude greater than that of exponential phase organisms. Removal of the wall from stationary phase organisms releases protoplasts with a sensitivity equal to that of exponential phase organisms, indicating that the phenotypic increase in resistance is caused by changes in the wall (Gale et al., 1975). Treatment of resistant cells with SH-binding agents such as iodoacetamide or $\mathrm{N}$-ethylmaleimide leads to increased resistance, whereas treatment with reducing agents such as $\beta$-mercaptoethanol results in a rapid decrease in resistance (Gale et al., 1975). The development of resistance in starved organisms aerated in a fermenter is dependent on the rate of aeration. If air is replaced by nitrogen at a time when resistance has increased to a s.r.c. value of 5 to $20 \mu \mathrm{g} \mathrm{AME} \mathrm{ml}^{-1}$, resistance decreases as the oxygen saturation of the medium falls, and rises again when aeration is resumed (Gale et al., 1977). Addition at the beginning of starvation of the antibiotics trichodermin or verrucarin, which inhibit protein synthesis in eukaryotic organisms, results in an increase in the rate at which resistance to AME develops.

After the cessation of growth considerable changes will take place in the pattern of metabolism in C. albicans, only some of which will be important in the development of phenotypic resistance to AME. The present paper describes changes that take place in the amino acid pool and in the carbohydrate content of $C$. albicans incubated under conditions which lead to AME resistance, and the effects of SH-reducing and SH-binding agents on that resistance. The resistance of organisms in the stationary phase of growth is at first affected by the presence of reducing substrates, especially glutamic acid, in the cells but, as these are exhausted, the resistance increases rapidly to high values which are unaffected by treatment with $\beta$-mercaptoethanol.

\section{METHODS}

Organism. Candida albicans strain 6406 was obtained from the Mycological Reference Laboratory, London School of Hygiene and Tropical Medicine, and was maintained, cultured and prepared in washed suspension as previously described (Gale, 1974).

Growth conditions. The organisms were grown in a continuous flow fermenter (FL 101, AB Biotec, Stockholm, Sweden), the medium supply was stopped and the organisms were aerated with stirring as previously described (Gale et al., 1977). For most of the experiments described below, the growth medium (YNBG) contained Difco Bacto yeast nitrogen base $\left(6.7 \mathrm{~g} \mathrm{I}^{-1}\right)$ with limiting glucose $(1 \%, \mathrm{w} / \mathrm{v})$, and incubation was carried out at $37^{\circ} \mathrm{C}$ in a stream of air flowing at $2.71 \mathrm{~min}^{-1}$ with the medium stirred at $1000 \mathrm{rev}$. $\mathrm{min}^{-1}$. Where indicated, sodium glutamate at 1 or $3 \mathrm{mg} \mathrm{ml}^{-1}$ or Difco vitamin-free Casamino acids at 3 or $10 \mathrm{mg} \mathrm{ml}^{-1}$ were added to the medium and the $\mathrm{pH}$ was maintained at a steady value (either 3 or 7) throughout growth and subsequent aeration. The rate of stirring, supply of medium, aeration, temperature and $\mathrm{pH}$ value were monitored and controlled by the appropriate accessories (LP100 Process Instrumentation Panel, AB Biotec). After inoculation, the organisms were grown for $16 \mathrm{~h}$ at which time continuous flow of medium $\left(D=0.15 \mathrm{~h}^{-1}\right)$ was started and continued for $36 \mathrm{~h}$. The supply of medium was then stopped but aeration, stirring, temperature and pH control were continued for up to $6 \mathrm{~d}$. Samples of culture were withdrawn at intervals, the absorbance was determined, and the organisms were prepared for determination of AME sensitivity, carbohydrate estimation or extraction of pool. There was no significant change in the absorbance of the culture for the first 3 to $4 \mathrm{~d}$ after the medium supply was stopped; subsequently there was sometimes a decrease with time.

Estimation of $K^{+}$release and $A M E$ sensitivity. The terms 'AME sensitivity' and 'AME resistance' refer to the action of $A M E$ in inducing leakage of $K^{+}$from suspensions of organisms, estimated by the use of a 
$\mathrm{K}^{+}$-sensitive electrode (Gale, 1974). Organisms were suspended at a final density of $1.0 \mathrm{mg}$ dry wt ml-1 in $0.03 \mathrm{M}$-Tris/ $\mathrm{HCl}$ buffer, $\mathrm{pH} \mathrm{7.5}$, and the concentration (s.r.c.) of AME which was needed to induce a standard rate of release equal to $1 \mathrm{nmol} \mathrm{K}^{+} \mathrm{min}^{-1}\left(\mathrm{mg}\right.$ dry wt organisms) ${ }^{-1}$ above that in the control without AME, in $8 \mathrm{~min}$ at $20^{\circ} \mathrm{C}$, was determined as previously described (Gale, 1974).

Amino acid analysis of 'pool'. Organisms were sedimented, washed once with water and the washed pellet was treated with $5 \%(\mathrm{w} / \mathrm{v})$ trichloroacetic acid (TCA) at $0{ }^{\circ} \mathrm{C}$ for $30 \mathrm{~min}$ to $2 \mathrm{~h}$. The TCA extract was washed six times with an equal volume of ether and the aqueous layer was passed through a Millipore filter to remove any residual debris. A volume of extract equivalent to $1 \mathrm{mg}$ dry wt organisms was then analysed in a Locarte bench model amino acid analyser (Locarte Co., London) calibrated against a standard amino acid mixture.

Treatment with $\mathrm{SH}$-reactive agents. Treatment was essentially the same as that used by Gale et al. (1975): organisms were centrifuged out of the growth medium and resuspended at a density of $1 \mathrm{mg}$ dry wt ml $\mathrm{ml}^{-1}$ in a medium containing (per litre) $2 \mathrm{~g} \mathrm{KH}_{2} \mathrm{PO}_{4}, 1 \mathrm{~g} \mathrm{NH}_{4} \mathrm{H}_{2} \mathrm{PO}_{4}$ and $10 \mathrm{~g}\left(\mathrm{NH}_{4}\right)_{2} \mathrm{HPO}_{4}$ and adjusted to a final $\mathrm{pH}$ of 6.5. Either $N$-ethylmaleimide (final concentration $1 \mathrm{mM}$ ) or $\beta$-mercaptoethanol (final concentration $0.2 \mathrm{M}$ ) was added to this medium and the organisms were incubated for $1 \mathrm{~h}$ at $37^{\circ} \mathrm{C}$ before being separated by centrifuging, washed and resuspended in $0.03 \mathrm{M}-\mathrm{Tris} / \mathrm{HCl}$ buffer, $\mathrm{pH} 7.5$, for $\mathrm{K}^{+}$release determination.

Cell fractionation and carbohydrate estimation. The quantitative determination of the major carbohydrate constituents of $C$. albicans was carried out using the method of Trevelyan \& Harrison (1956) as described by Herbert et al. (1971). Washed organisms ( $25 \mathrm{mg}$. dry wt) were extracted with $2.5 \mathrm{ml} 0.5 \mathrm{M}$-TCA for $1 \mathrm{~h}$ at $0{ }^{\circ} \mathrm{C}$ and centrifuged. The extract contained the low molecular weight carbohydrates. The pellet, after removal of RNA by extraction with $0.5 \mathrm{M}$-perchloric acid for $90 \mathrm{~min}$ at $37^{\circ} \mathrm{C}$, was extracted with $0.25 \mathrm{M}-\mathrm{Na}_{2} \mathrm{CO}_{3}$ for $45 \mathrm{~min}$ at $100^{\circ} \mathrm{C}$. This extract contained the mannan and alkali-soluble glucan. It was divided into two parts: one was used for determination of the total alkali-soluble carbohydrate and the other for determination of the mannan after precipitation as the insoluble mannan-copper complex following addition of $\mathrm{KOH}$ (final concentration $1 \mathrm{M}$ ) and Fehlings solution to the extract. The precipitated mannan was dissolved in $1 \mathrm{M}^{-\mathrm{H}_{2} \mathrm{SO}_{4}}$ prior to carbohydrate assay. The cell residue was further extracted with $0.5 \mathrm{M}$-perchloric acid for $30 \mathrm{~min}$ at $100{ }^{\circ} \mathrm{C}$. This extract contained the acid-soluble glucan. The final cell residue containing glucan (and chitin) was resuspended in $2 \mathrm{M}-\mathrm{NaOH}$ prior to carbohydrate assay.

The total carbohydrate present in each fraction was assayed using the anthrone reagent by the method described by Herbert et al. (1971). Glucose standards were assayed concurrently with the samples and the values for the mannan fraction were corrected for the lower absorbance $(55 \%)$ that this carbohydrate gives relative to glucose.

Glutamate dehydrogenase. Glutamate dehydrogenase activities were determined on extracts of $C$. albicans by a spectrophotometric method based on that described by Nunez de Castro et al. (1970). Organisms were harvested, washed and resuspended at a density of approximately $50 \mathrm{mg} \mathrm{dry} \mathrm{wt} \mathrm{ml}^{-1}$ in $0.1 \mathrm{M}$-citric acid/ $\mathrm{Na}_{2} \mathrm{HPO}_{4}$ buffer at $\mathrm{pH} 8.0$ or 6.0 . The suspension was mixed with glass beads $(0.5 \mathrm{~mm}$ diam.) and subjected to vigorous agitation on a Whirlimixer (Scientific Industries International) for $2 \mathrm{~min}$. Breakage was assessed by examination under the microscope and was always complete in $2 \mathrm{~min}$. The broken material was centrifuged at $2000 \mathrm{~g}$ for $30 \mathrm{~min}$ and the supernatant fluid was used as enzyme extract.

The assay mixture contained $1.3 \mathrm{ml} 0.1 \mathrm{M}$-citric acid/ $\mathrm{Na}_{2} \mathrm{HPO}_{4}$ buffer, $\mathrm{pH} 8.0$ or $6 \cdot 0,0.1 \mathrm{ml} 0.9 \mathrm{M}$-sodium 2-oxoglutarate, $0.5 \mathrm{ml} 0.6 \mathrm{M}-\mathrm{NH}_{4} \mathrm{Cl}$ and $0.25 \mathrm{ml}$ enzyme extract; the mixture was incubated for $12 \mathrm{~min}$ before adding either NADH (final concentration $0.85 \mathrm{~mm}$ ) or NADPH (final concentration $1.34 \mathrm{~mm}$ ), and the decrease in absorbance at $340 \mathrm{~nm}$ was followed over $6 \mathrm{~min}$ using a Cary spectrophotometer (Varian Instrument Division, Palo Alto, California, U.S.A.). This was corrected for the decrease in absorbance in a suitable blank. Enzyme activity was expressed as nmol substrate oxidized min $^{-1}$ (mg dry wt organisms extracted) $)^{-1}$.

Estimation of $\mathrm{NAD}^{+} / \mathrm{NADH}$ in $\mathrm{C}$. albicans. $\mathrm{NAD}^{+}$and $\mathrm{NADH}$ were assayed fluorimetrically according to the method of Estabrook et al. (1967). Samples (4 ml, 20 to $40 \mathrm{mg}$ dry wt organisms) were mixed rapidly with either $2 \mathrm{ml} 15 \%(\mathrm{v} / \mathrm{v})$ perchloric acid (for $\mathrm{NAD}^{+}$extraction) or $1 \mathrm{ml} 2 \mathrm{M}$-ethanolic $\mathrm{KOH}$ (for NADH extraction). Acid extracts were neutralized with $0.4 \mathrm{M}$-triethanolamine in $1.8 \mathrm{M}-\mathrm{KOH}$ and suitable samples were diluted to $2 \mathrm{ml}$ with a mixture containing $0.2 \mathrm{M}$-glycine, $0.4 \mathrm{M}$-hydrazine hydrate and $0.15 \mathrm{M}$-ethanol; the increase in fluorescence on addition of $0.15 \mathrm{ml}$ alcohol dehydrogenase $\left(100 \mathrm{units}^{-1} \mathrm{ml}^{-1}\right)$ was observed and calibrated by comparison with the effect of addition of $20 \mathrm{nmol} \mathrm{NAD}^{+}$to a similar sample.

Alkaline extracts were neutralized with $1 \mathrm{M}$-triethanolamine. $\mathrm{HCl}$ and samples were diluted to $2.5 \mathrm{ml}$

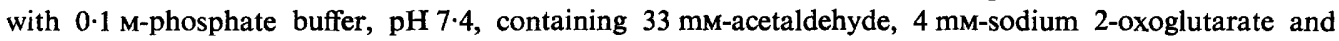
$4 \mathrm{mM}-\mathrm{NH}_{4} \mathrm{Cl}$; the decrease in fluorescence on addition of $25 \mu \mathrm{l}$ alcohol dehydrogenase $\left(100\right.$ units $\left.\mathrm{ml}^{-1}\right)$ was measured and calibrated by comparison with the effect of addition of $20 \mathrm{nmol} \mathrm{NADH}$ to a similar sample.

All solutions were passed through Millipore filters (pore size $0.22 \mu \mathrm{m}$ ) and reaction mixtures were allowed to equilibrate to a basal level of fluorescence before assay. Fluorescence was measured with an AmincoBowman (Silver Springs, Maryland, U.S.A.) spectrofluorimeter, with ratio photometer attachment, at an excitation wavelength of $340 \mathrm{~nm}$ and emission wavelength of $420 \mathrm{~nm}$. 
Lipid. Organisms were centrifuged to form a pellet and this was taken up in $0.5 \mathrm{ml}$ methanol; $2 \mathrm{ml}$ chloroform/methanol $(2: 1, \mathrm{v} / \mathrm{v})$ was then added and the mixture was left for $3 \mathrm{~h}$ at room temperature. The mixture was centrifuged, the solvent fraction was collected and the pellet was re-extracted with chloroform/methanol for $3 \mathrm{~h}$ at room temperature and again overnight at $4{ }^{\circ} \mathrm{C}$. The extracts were combined, taken to dryness and the lipid was determined gravimetrically.

Chemicals. Amphotericin B methyl ester was kindly provided by Professor C. P. Schaffner of Rutgers University, U.S.A., and also by Dr W. E. Brown of E. R. Squibb \& Sons, Princeton, N.J., U.S.A.

\section{RESULTS}

Changes in the amino acid pool of $C$. albicans during starvation

Freshly prepared YNBG medium has a pH value of 5.6. During growth and subsequent starvation, as described under Methods, the $\mathrm{pH}$ falls to approximately 3 . When glutamate or Casamino acids are added to the medium, the $\mathrm{pH}$, unless controlled, falls during the early stages of growth to around 3 to 4 and then rises to 7 to 8 during subsequent starvation and aeration. To avoid changes due to varying $\mathrm{pH}$, the $\mathrm{pH}$ of the culture was maintained either at 3 or 7 throughout growth and subsequent starvation.

\section{Growth, aeration and starvation at $\mathrm{pH} 3$}

Changes in the amino acid pool. Table 1 shows the changes that take place in the composition of the amino acid pool extracted by cold TCA from $C$. albicans aerated under starvation conditions. As explained under Methods, the culture was grown for 24 to $36 \mathrm{~h}$ with a continuous supply of medium $\left(D=0.15 \mathrm{~h}^{-1}\right)$, the supply was then stopped $(t=0$, Table 1) and aeration was continued. Samples of culture were withdrawn at $24 \mathrm{~h}$ intervals, and the organisms were separated by centrifuging and analysed for their amino acid pool composition, carbohydrate content and AME sensitivity. When the growth medium was YNBG, amino acids fell into three groups based on the type of change that occurred in their concentration in the amino acid pool during starvation: (1) a steady fall in concentration, as for glutamate; (2) a rise in concentration during the first 24 to $72 \mathrm{~h}$ of aeration followed by a decrease; the rise might occur during the first $24 \mathrm{~h}$ as for glycine, serine or cysteine, or take longer as for alanine, lysine, histidine, isoleucine, methionine or valine; (3) little variation with time, the trend being a small rise during the first 48 to $72 \mathrm{~h}$ followed by a later decrease, as for arginine or threonine. A rapid rise in AME resistance occurred at a time when the pool concentration of glutamate had fallen to a low value and the concentrations of the amino acids in group 2 were also decreasing (see Fig. $1 a, b$ and Table 1).

Early experiments in which the conditions of growth before starvation were varied showed an apparent correlation between the glutamate content of the pool and the development of resistance during aeration; no correlation between resistance and any other amino acid in the pool could be seen. Attempts were therefore made to alter the glutamate concentration in the pool by variations in the growth medium.

$A M E$ resistance and the concentration of glutamate in the pool. Organisms were grown in YNBG medium supplemented with sodium glutamate at either 1 or $3 \mathrm{mg} \mathrm{ml}^{-1}$ or with Casamino acids at $10 \mathrm{mg} \mathrm{ml}^{-1}$. The supply of medium was stopped, aeration was continued, and samples were taken at $24 \mathrm{~h}$ intervals for estimation of the AME sensitivity and the amino acid content of the pool. Figure $1(a)$ shows the development of AME resistance in typical cultures and Fig. 1(b) the corresponding changes in the glutamate content of the pool with time of starvation. In a series of separate runs spread over 5 months, s.r.c. values obtained after $4 \mathrm{~d}$ starvation and aeration were 30,18, 23, 16 and 21 (mean 21.6) after growth in YNBG alone, 10, 5, 8 and 4 (mean 6.8) after growth in YNBG plus $3 \mathrm{mg}$ sodium glutamate $\mathrm{ml}^{-1}$ and 19, 7 and 14 (mean 13) after growth in YNBG plus $10 \mathrm{mg}$ Casamino acids $\mathrm{ml}^{-1}$. Addition of glutamate to the growth medium resulted in an increased concentration of glutamate in the pool during the early stages of starvation and in a delay in the onset of 


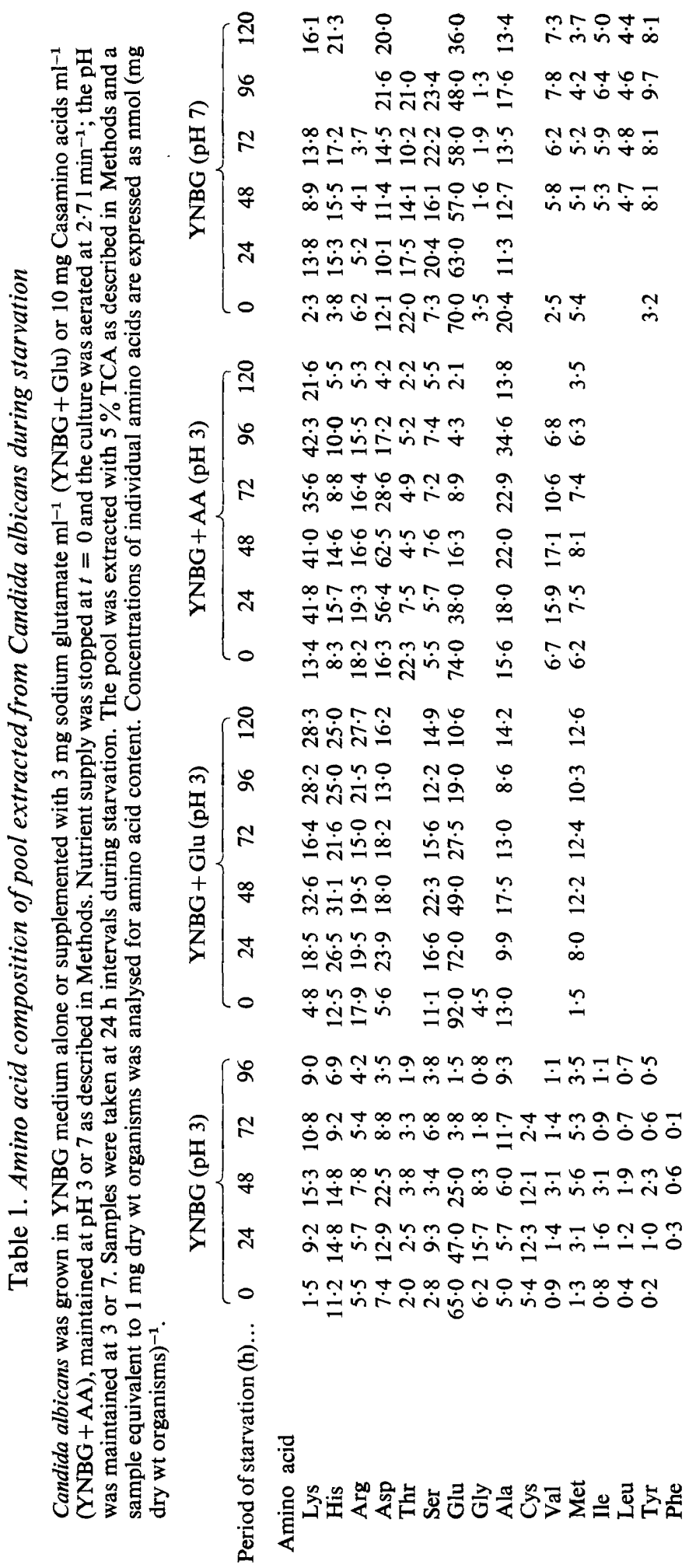



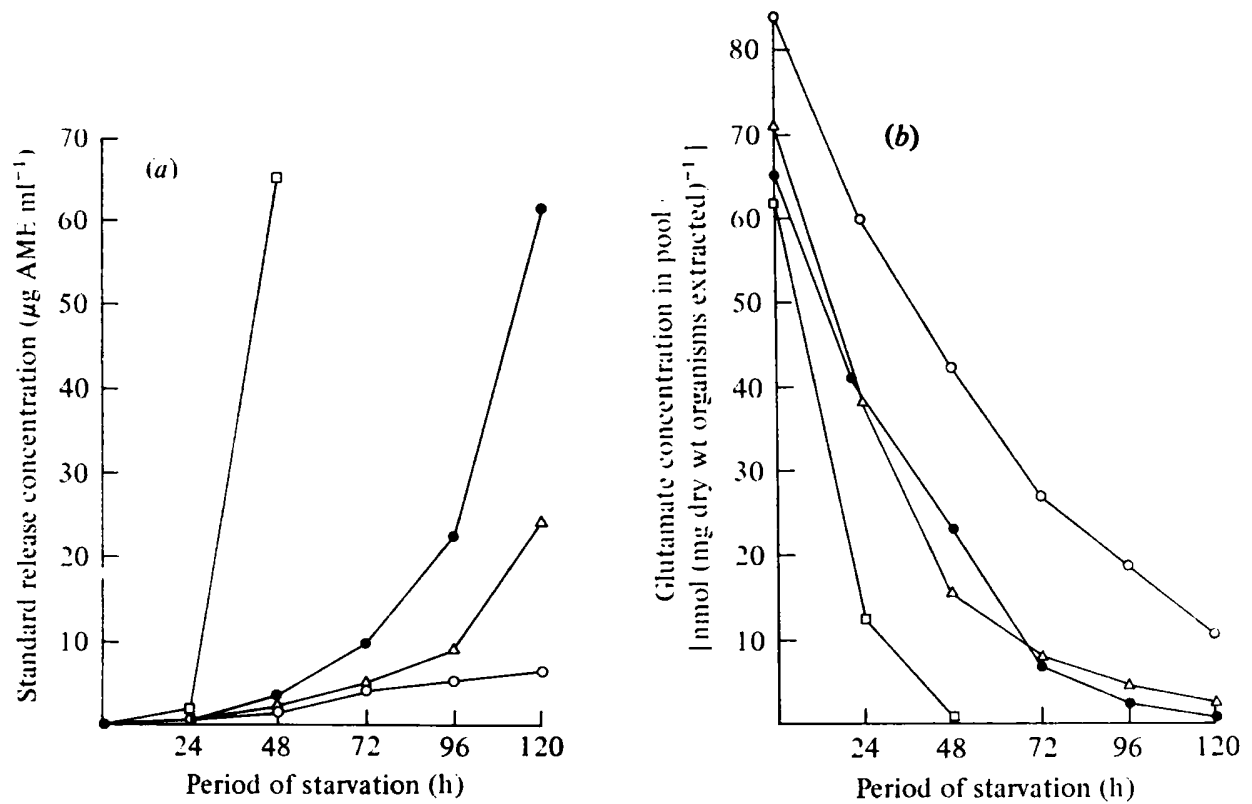

Fig. 1. Variation of development of resistance to AME $(a)$ and glutamate content of the amino acid pool (b) during starvation of Candida albicans following growth in different media maintained at pH 3:, YNBG; $O$, YNBG plus $3 \mathrm{mg}$ sodium glutamate $\mathrm{ml}^{-1} ; \triangle$, YNBG plus $10 \mathrm{mg}$ Casamino acids $\mathrm{ml}^{-1} ; \square$, YNBG (with $5 \mu \mathrm{g}$ trichodermin $\mathrm{ml}^{-1}$ added at $t=0$ ). At $t=0$, the medium flow was stopped and the culture was aerated at $2.71 \mathrm{~min}^{-1}$ and maintained at pH 3. Samples were withdrawn at $24 \mathrm{~h}$ intervals for ( $a$ ) determination of AME sensitivity, expressed as the standard release

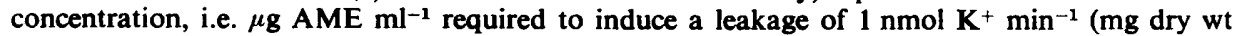
organisms) ${ }^{-1}$ over the rate in controls without AME (Gale, 1974), and (b) amino acid analysis of the TCA-extractable pool as described in Methods, glutamate concentration being expressed as nmol (mg dry wt organisms extracted) ${ }^{-1}$.

resistance. In each case, resistance did not rise above an s.r.c. of 10 until the pool glutamate concentration had fallen to $10 \mathrm{nmol}$ (mg dry wt organisms) ${ }^{-1}$ or less.

Figure 2 shows a plot of resistance against glutamate concentration in the pool; computer analysis gives a highly significant correlation by Fisher's $Z$ test (Fisher, 1936) between the two variables $[N=58$, correlation coefficient $=0 \cdot 64, T=6 \cdot 19, Z /($ standard error of $Z)=$ 5.585 , probability $<0.01$ ]. Figure 3 shows that there is a linear correlation between the rate of disappearance of glutamate from the pool and the s.r.c. for values of the latter between 1 and 15, i.e. for organisms starved between 24 and $96 \mathrm{~h}[N=45$, correlation coefficient $=$ $0.81, T=8.68, Z /($ standard error of $Z)=7.0726$, probability $<0.01]$. No correlation could be found between the s.r.c and the corresponding values for any other amino acid in the pool.

Gale et al. (1977) found that the development of AME resistance was increased by the presence of inhibitors of protein synthesis such as trichodermin and verrucarin. Figure 1 includes values from an experiment in which $5 \mu \mathrm{g}$ trichodermin $\mathrm{ml}^{-1}$ was added to the culture at the beginning of starvation; the markedly increased rate of development of resistance was again accompanied by an enhanced rate of disappearance of glutamate from the pool.

Effect of treatment of organisms with $N$-ethylmaleimide or $\beta$-mercaptoethanol. Gale et al. (1975), working with C. albicans having moderate levels of resistance to AME (s.r.c. between 4 and 10), showed that treatment of the organisms with $N$-ethylmaleimide (NEM) markedly increased resistance (s.r.c. 20 to 40 ) while incubation with mercaptoethanol (ESH) decreased the s.r.c. to 1 or less. The effects of such treatments on organisms harvested during the starvation period are shown in Fig. 4. Treatment with NEM increased the AME resistance 


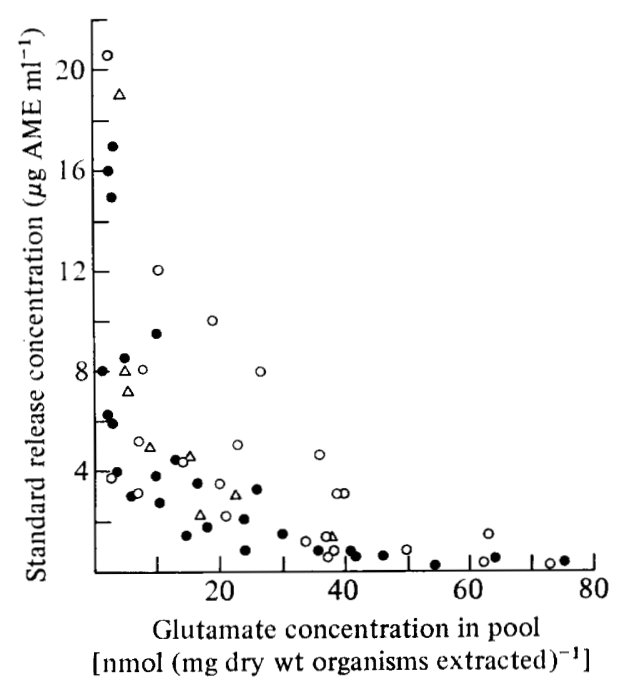

Fig. 2

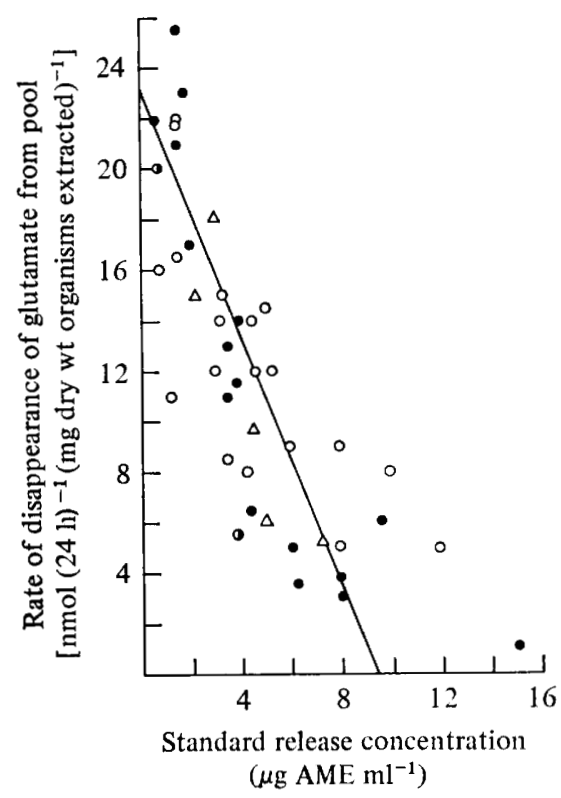

Fig. 3

Fig. 2. Relationship between resistance to AME and concentration of glutamate in the pool of Candida albicans during starvation. Conditions as for Fig. 1. Growth media:, YNBG; $\bigcirc$, YNBG plus $3 \mathrm{mg}$ sodium glutamate $\mathrm{ml}^{-1} ; \triangle$, YNBG; plus $10 \mathrm{mg}$ Casamino acids $\mathrm{ml}^{-1}$.

Fig. 3. Correlation between resistance to $A M E$ and the rate of disappearance of glutamate from the pool of Candida albicans. Conditions as for Fig. 1. Growth media:, YNBG; O, YNBG plus $3 \mathrm{mg}$

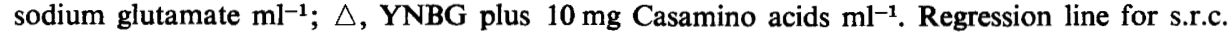
$(=X)$ against $\mathrm{dGlu} / \mathrm{d} t(=Y): X=9 \cdot 34-0 \cdot 4 Y$.

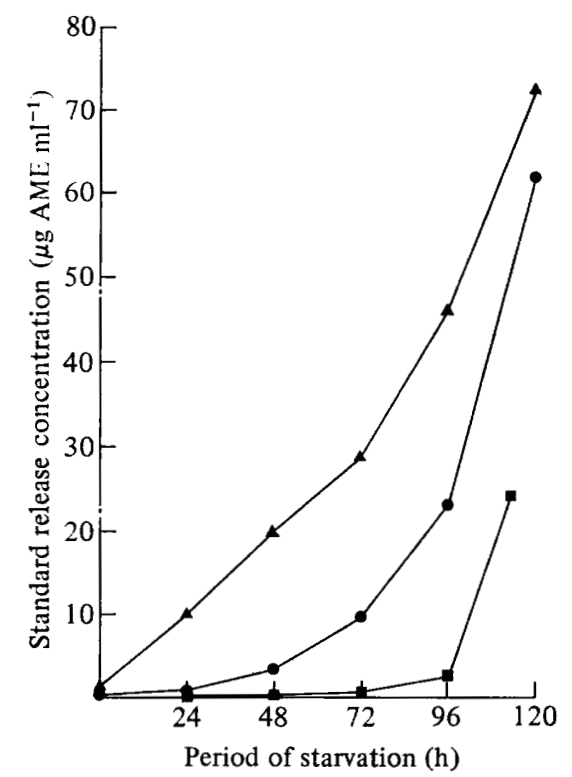

Fig. 4. Effect of treatment with $N$-ethylmaleimide $(\boldsymbol{\Delta})$ or $\beta$-mercaptoethanol $(\boldsymbol{\square})$ on the resistance to AME of Candida albicans during starvation following growth in YNBG medium (, , untreated organisms). Conditions as for Fig. 1. After harvesting, the organisms were resuspended at a final concentration of $1 \mathrm{mg}$ dry wt ml-1 in a phosphate buffer at $\mathrm{pH} 6.5$ (see Methods) in the presence of either $1 \mathrm{mM}-N$-ethylmaleimide or $0.2 \mathrm{M}$ - $\beta$-mercaptoethanol and incubated at $37^{\circ} \mathrm{C}$ for $1 \mathrm{~h}$ before being separated by centrifuging, washed and assayed for AME sensitivity as in Fig. 1. 


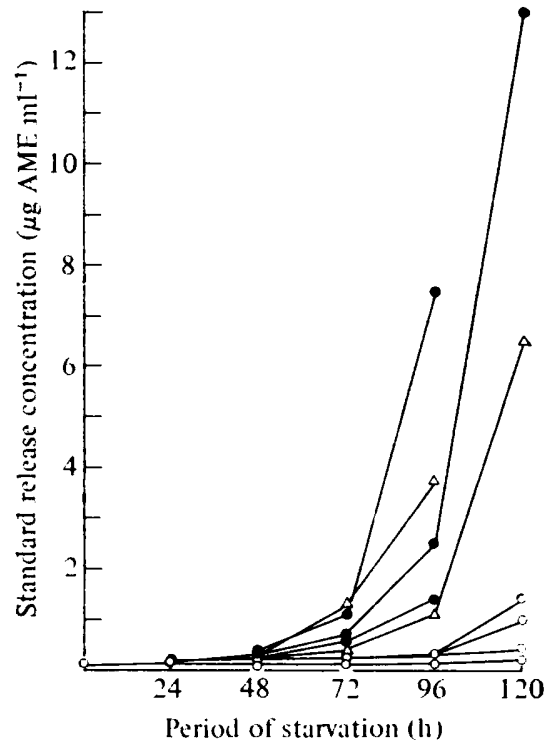

Fig. 5

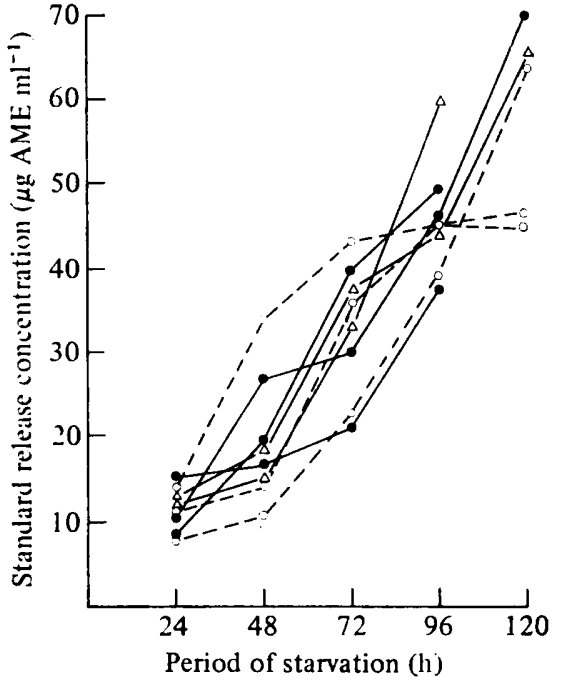

Fig. 6

Fig. 5. Resistance to AME of Candida albicans starved after growth in various media and treated, after harvesting, with $\beta$-mercaptoethanol. Conditions as for Figs 1 and 4. Growth media: $O$, YNBG; $O$, YNBG plus $3 \mathrm{mg}$ sodium glutamate $\mathrm{ml}^{-1} ; \triangle, Y N B G$ plus $10 \mathrm{mg}$ Casamino acids $\mathrm{ml}^{-1}$.

Fig. 6. Resistance to AME of Candida albicans starved after growth in various media and treated, after harvesting, with $N$-ethylmaleimide. Conditions as for Figs 1 and 4 . Growth media:, YNBG; $\bigcirc$, YNBG plus $3 \mathrm{mg}$ sodium glutamate $\mathrm{ml}^{-1} ; \triangle$, YNBG plus $10 \mathrm{mg}$ Casamino acids $\mathrm{ml}^{-1}$.

of all samples, the increase ranging from 10 -fold for $24 \mathrm{~h}$ samples to less than 2 -fold for organisms aerated for $120 \mathrm{~h}$. Treatment with ESH of organisms aerated for 48 to $72 \mathrm{~h}$ decreased the s.r.c. almost to that of exponentially growing organisms but longer periods of starvation yielded organisms in which the s.r.c. was 20 or more even after ESH treatment. When starvation and aeration were continued until the s.r.c. had risen above 100 , treatment with ESH did not produce any significant reduction in that resistance.

NEM and ESH treatments were also applied to organisms initially grown in media supplemented with glutamate or Casamino acids. The development of AME resistance in untreated organisms has been described above (Fig. 1 a). Figure 5 shows the resistance of organisms after treatment with ESH. S.r.c. values were less than those of untreated cells in all cases but showed a major increase in those organisms which had been starved and aerated for $96 \mathrm{~h}$ or longer. The presence of glutamate during growth delayed the onset of this increase. Figure 6 shows the s.r.c. of the same cultures when the organisms were treated with NEM. Allowing for considerable error in sampling, treatment and estimation, the results in Fig. 6 are not inconsistent with a steady increase in resistance (after NEM treatment) during starvation-aeration which is not markedly affected by the environmental conditions.

\section{Growth, aeration and starvation at pH 7}

Table 2 summarizes the s.r.c. values obtained for $C$. albicans grown and starved at $\mathrm{pH} 7$ in YNBG alone or supplemented with either sodium glutamate or Casamino acids, the organisms being tested immediately and after treatment with NEM or ESH. When starvation and aeration took place at $\mathrm{pH} 7$, resistance developed more slowly than in the corresponding experiments where the $\mathrm{pH}$ was maintained at 3 . After $120 \mathrm{~h}$ aeration and starvation, organisms maintained at $\mathrm{pH} 7$ had s.r.c. values of 2.5 to 3.5 compared with 50 or greater for organisms at $\mathrm{pH}$. In one experiment, aeration was continued for $8 \mathrm{~d}$ at $\mathrm{pH} 7$ by which time the s.r.c. 
Table 2. Sensitivity to AME of Candida albicans, before and after treatment with $N$-ethylmaleimide (NEM) or $\beta$-mercaptoethanol (ESH), following growth, starvation and aeration at $\mathrm{pH} 7$

Candida albicans was grown in YNBG alone or supplemented with 3 mg sodium glutamate $\mathrm{ml}^{-1}$ (YNBG + Glu) or $10 \mathrm{mg}$ Casamino acids $\mathrm{ml}^{-1}$ (YNBG + AA), as in Table 1, but with the pH maintained at 7; nutrient supply was stopped at $t=0$ and the $\mathrm{pH}$ was maintained at 7 throughout subsequent aeration. Samples were removed at $24 \mathrm{~h}$ intervals and organisms were prepared for estimation of s.r.c., i.e. $\mu \mathrm{g} \mathrm{AME} \mathrm{m}{ }^{-1}$ required to induce release of $1 \mathrm{nmol} \mathrm{K}^{+} \mathrm{min}^{-1}$ (mg dry wt

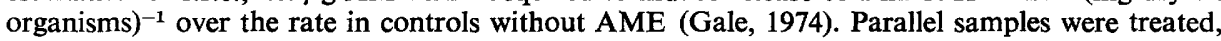
before assay, with NEM or ESH as described in Methods. In one experiment, organisms were grown in YNBG and $20 \mu \mathrm{g}$ trichodermin $\mathrm{ml}^{-1}$ was added at $t=0$.

\begin{tabular}{|c|c|c|c|c|c|c|c|c|c|c|c|c|c|c|c|}
\hline \multirow{2}{*}{$\begin{array}{c}\text { Period of } \\
\text { starvation }(h) \ldots\end{array}$} & \multicolumn{4}{|c|}{ YNBG } & \multicolumn{3}{|c|}{ YNBG + Glu } & \multicolumn{3}{|c|}{$\mathrm{YNBG}+\mathrm{AA}$} & \multicolumn{5}{|c|}{ YNBG (+trichodermin) } \\
\hline & 24 & 48 & 96 & 120 & 48 & 96 & 120 & 48 & 96 & 120 & 24 & 48 & 72 & 96 & 120 \\
\hline \multicolumn{16}{|c|}{ S.r.c. $\left(\mu \mathrm{g} \mathrm{AME} \mathrm{ml}^{-1}\right)$} \\
\hline & $0 \cdot 28$ & 0.5 & 1.55 & 2 & 0 . & $1 \cdot 7$ & 1. & 0.35 & 0.35 & & & & & & $4 \cdot 5$ \\
\hline & $2 \cdot 1$ & 3.9 & 3.9 & $5 \cdot 3$ & 4.9 & $4 \cdot 5$ & $4 \cdot 2$ & $2 \cdot 2$ & $1 \cdot 2$ & 1 & & 0.75 & $1 \cdot 45$ & 2 & $2 \cdot 0$ \\
\hline -treated & 0.08 & 0.36 & 0.4 & 0.85 & $0 \cdot 1$ & $0 \cdot 15$ & 0.5 & $0 \cdot 1$ & 0.16 & 0.25 & $0 \cdot 16$ & 0.24 & 0.9 & $1 \cdot 2$ & $1 \cdot 2$ \\
\hline
\end{tabular}

had risen to 20. Initial growth in media supplemented with glutamate or Casamino acids resulted in a still slower development of resistance during starvation; after $120 \mathrm{~h}$ the s.r.c. of organisms grown in the presence of glutamate or Casamino acids was 1.5 or 0.8 , respectively. Treatment with NEM or ESH had qualitatively the same effects as those described for organisms grown and starved at $\mathrm{pH} 3$.

Table 1 shows that the concentration of glutamate in the pool of organisms grown in YNBG and subsequently starved for $120 \mathrm{~h}$ at $\mathrm{pH} 7$ had fallen to $36 \mathrm{nmol}$ (mg dry wt organisms) ${ }^{-1}$, a value well above that at which the resistance begins to rise rapidly in organisms at $\mathrm{pH} 3$. The concentrations of glutamate in the pool of organisms initially grown in supplemented media were higher at all times than those in organisms grown in YNBG alone.

The addition of $20 \mu \mathrm{g}$ trichodermin $\mathrm{ml}^{-1}$ to cultures starved at $\mathrm{pH} 7$ was not followed by the marked and rapid rise in resistance obtained at $\mathrm{pH} 3$ (Fig. 1a), the s.r.c. after $96 \mathrm{~h}$ being approximately twice that in the control without antibiotic (Table 2). Treatment with ESH decreased resistance but NEM-treated organisms had s.r.c. values the same or less than those of untreated organisms. Thus the effects of trichodermin on organisms maintained at pH 7 were qualitatively but not quantitatively the same as those for organisms maintained at $\mathrm{pH} 3$.

\section{Glutamate dehydrogenase activities}

The data provided in the previous sections suggest that the rate of metabolism of glutamate in the pool of the organisms may be a major factor in determining the sensitivity to AME of $C$. albicans during the first few days of starvation. Previous work has shown that sensitivity is also affected by the oxygen saturation of the medium and the state of reduction of the organisms (Gale et al., 1975); it therefore seems possible that glutamate acts as a source of reducing potential. Glutamate acts as substrate for two dehydrogenase activities: glutamate: $\mathrm{NAD}^{+}$oxidoreductase (EC 1.4.1.2) and glutamate: NADP ${ }^{+}$oxidoreductase (EC 1.4.1.3), the former being mainly concerned with glutamate breakdown and the latter with glutamate synthesis (Holzer, 1966). The two activities were determined in organisms grown under the various conditions described above.

Reaction $p H$. Activities of extracts were determined over the $\mathrm{pH}$ range 5 to 8. Both NADand NADP-linked enzymes showed optimum activity at $\mathrm{pH} 8$ whether organisms were

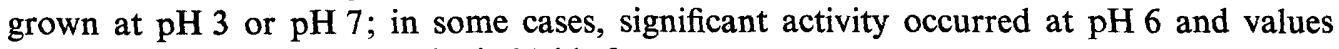
are quoted for both pH 6 and 8 in Table 3. 
Table 3. Effect of growth conditions on glutamate dehydrogenase activities of Candida albicans

Candida albicans was grown in batch culture in a rotary incubator at $37^{\circ} \mathrm{C}$ in YNBG medium alone or supplemented with glutamate (Glu) or Casamino acids (AA), at pH 3 or 7; in each case, organisms were harvested towards the end of the exponential growth phase, and extracts were prepared for the estimation of NAD- and NADP-linked glutamate dehydrogenase as described in Methods. Enzyme assays were carried out at pH 8 and (values in parentheses) pH 6. Activities are expressed as nmol substrate oxidized $\min ^{-1}$ (mg dry wt organisms extracted $)^{-1}$. Each activity is the mean of two cultures grown under the conditions specified.

Addition to YNBG medium

None

$1 \mathrm{mg} \mathrm{Glu} \mathrm{ml} \mathrm{m}^{-1}$

$3 \mathrm{mg} \mathrm{Glu} \mathrm{ml}^{-1}$

$3 \mathrm{mg} \mathrm{AA} \mathrm{ml}^{-1}$

$10 \mathrm{mg} \mathrm{AA} \mathrm{ml}^{-1}$
pH 3

$\begin{array}{ll}\text { NAD } & \text { NADP } \\ 119 & 1320 \\ 112 & 980(50) \\ 158 & 1140 \\ 183(50) & 1010 \\ 600(55) & 410(100)\end{array}$

pH 7

$\begin{array}{ll}\overbrace{\text { NAD }} & \text { NADP } \\ 138 & 565 \\ 140(107) & 420(130) \\ 150 & 640(220) \\ 172(175) & 550(65) \\ 245(17) & 215(62)\end{array}$

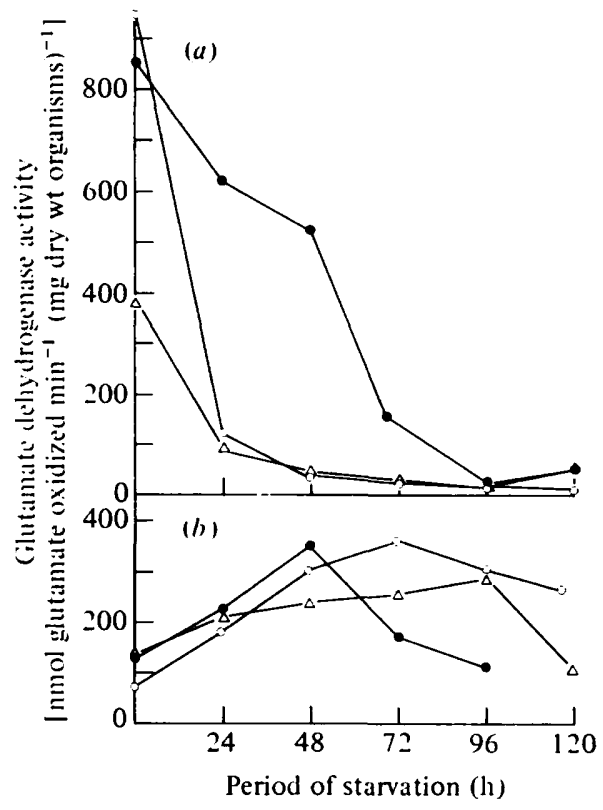

Fig. 7. Glutamate dehydrogenase activities of Candida albicans during starvation and aeration following growth in various media: (a) NADP-linked dehydrogenase; (b) NAD-linked dehydrogenase. Conditions as for Fig. 1. Growth media:, YNBG; $\bigcirc$, YNBG plus $3 \mathrm{mg}$ sodium glutamate $\mathrm{ml}^{-1} ; \triangle$, YNBG plus $10 \mathrm{mg}$ Casamino acids $\mathrm{ml}^{-1}$. After harvesting, extracts of organisms were prepared and dehydrogenase activities were determined as described in Methods.

Effect of $p H$ and composition of growth medium. Organisms were grown in batch culture to late-exponential phase, the cultures being held at either $\mathrm{pH} 7$ or 3 by suitable buffers. Table 3 shows that the addition to YNBG of sodium glutamate (final concentration either 1 or $3 \mathrm{mg} \mathrm{ml}^{-1}$ ) had little effect on the activity (expressed per mg dry wt organisms) of either the NAD- or the NADP-linked enzyme whereas the addition of Casamino acids at $10 \mathrm{mg}$ $\mathrm{ml}^{-1}$ increased the activity of the NAD-linked enzyme and decreased that of the NADPlinked enzyme. The pH maintained during growth had no significant effect on the activity of the NAD-linked dehydrogenase, except in the medium containing $10 \mathrm{mg}$ Casamino acids $\mathrm{ml}^{-1}$ where the enzyme activity of organisms grown at $\mathrm{pH} 7$ was less than half that in 


\section{Table 4. Carbohydrate composition of Candida albicans during starvation following growth in YNBG medium at $\mathrm{pH} 3$}

The medium flow was stopped and the culture was aerated at $2.71 \mathrm{~min}^{-1}$. Samples were withdrawn at $24 \mathrm{~h}$ intervals and the constituent carbohydrates were determined as described in Methods.

$\begin{array}{lcccc}\text { Period of starvation (h) } & \begin{array}{c}\text { Soluble } \\ \text { glucan }\end{array} & \text { Mannan } & \begin{array}{c}\text { Insoluble } \\ \text { glucan }\end{array} & \begin{array}{c}\text { Total } \\ \text { [ } \mu \text { g (mg dry wt } \\ \text { organisms) }\end{array} \\ \text { Exponential culture } & 57 & 23 & 20 & 230 \\ 24 & 41 & 29 & 30 & 190 \\ 48 & 44 & 27 & 29 & 210 \\ 72 & 45 & 26 & 29 & 210 \\ 96 & 41 & 28 & 31 & 190\end{array}$

organisms grown at $\mathrm{pH} 3$. The activity of the NADP-linked dehydrogenase, estimated at $\mathrm{pH} 8$, in organisms grown at $\mathrm{pH} 7$, was approximately half that of organisms grown at $\mathrm{pH} 3$. Activities estimated at $\mathrm{pH} 6$ were in general greater in organisms from cultures grown at $\mathrm{pH} 7$ than from those grown at $\mathrm{pH} 3$.

Changes in glutamate dehydrogenase activities during starvation. Figure 7 shows the changes that take place with time in the glutamate dehydrogenase activities of organisms harvested from cultures maintained under conditions of starvation and aeration as described in the first section above. Time 0 in Fig. 7 corresponds to the time when the flow of medium was stopped while aeration and $\mathrm{pH}$ maintenance were continued. The activity of the NADPlinked enzyme (Fig. $7 a$ ) decreased sharply during the first 48 to $72 \mathrm{~h}$ starvation, whereas that of the NAD-linked enzyme (Fig. $7 b$ ) increased during the first 48 to $72 \mathrm{~h}$ and then decreased although activity did not fall below that at time 0 during the 96 to $120 \mathrm{~h}$ experimental period. The same pattern of changes was obtained whether cultures were maintained at $\mathrm{pH} 3$ or 7 in the presence or absence of trichodermin.

\section{Changes in other metabolizable components}

Lipid. Lipid was extracted and determined gravimetrically on samples ( $25 \mathrm{mg}$ dry wt organisms) harvested after growth in YNBG medium. At the beginning of starvation, the lipid content was $0.765 \pm 0.07$ and after $4 \mathrm{~d}$ starvation and aeration, $0.745 \pm 0.05 \mathrm{mg}(25 \mathrm{mg}$ dry wt organisms) ${ }^{-1}$.

Cellular carbohydrates. The changes in the major carbohydrate constituents of C. albicans during prolonged incubation after the cessation of growth are shown in Table 4. Since Northcote \& Horne (1952) and Northcote (1953) found no physiological or chemical differences between the alkali-soluble and the acid-soluble glucan fractions, the values for the carbohydrate content of these fractions have been combined. There was an initial fall in the soluble glucan fraction during the first $24 \mathrm{~h}$ after the cessation of growth and thereafter the value for this fraction remained approximately constant. The ratio of mannan to residual glucan remained constant during the incubation. The total carbohydrate content of the organisms fell by a small but variable amount during the course of the incubation. This pattern of changes was not significantly affected by either the $\mathrm{pH}$ or the complexity of the growth medium. In 13 experiments the average decrease in soluble glucan during the first $24 \mathrm{~h}$ starvation was $32 \pm 15 \%$, and that in total carbohydrate during the first $96 \mathrm{~h}$ was $20 \pm 7 \%$. The ratio of mannan to insoluble glucan in organisms grown in the presence or absence of sodium glutamate at either $\mathrm{pH} 3$ or 7 was $1 \cdot 1 \pm 0 \cdot 12$. However the ratio for

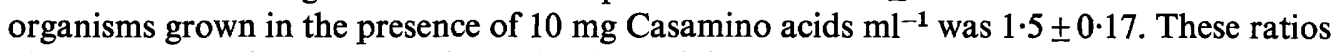
did not change during starvation. The dry weights of organisms in suspension were determined by measuring the absorbance of a suitably diluted suspension and the fall in total 
Table 5. Reduction of NAD in Candida albicans and resistance of the organism to AME

\begin{tabular}{|c|c|c|c|c|c|c|c|c|}
\hline \multirow[b]{2}{*}{$\begin{array}{c}\text { Period of } \\
\text { starvation (h) }\end{array}$} & \multicolumn{4}{|c|}{ YNBG } & \multicolumn{4}{|c|}{ YNBG + Glu } \\
\hline & NADH & $\mathrm{NAD}^{+}$ & $\begin{array}{l}\text { NADH/ } \\
\text { NAD }^{+}\end{array}$ & S.r.c. & NADH & NAD $^{+}$ & $\begin{array}{l}\text { NADH/ } \\
\text { NAD }^{+}\end{array}$ & S.r.c \\
\hline 0 & 0.63 & 0.41 & $1 \cdot 54$ & $0 \cdot 3$ & $0 \cdot 30$ & $0 \cdot 21$ & $1 \cdot 43$ & $0 \cdot 2$ \\
\hline 24 & $0 \cdot 82$ & $1 \cdot 47$ & 0.56 & $1 \cdot 6$ & & & & $1 \cdot 5$ \\
\hline 48 & $0 \cdot 88$ & $2 \cdot 22$ & $0 \cdot 4$ & $3 \cdot 8$ & $1 \cdot 02$ & $1 \cdot 81$ & $0 \cdot 56$ & $3 \cdot 1$ \\
\hline 72 & $0 \cdot 83$ & $2 \cdot 22$ & $0 \cdot 37$ & $8 \cdot 0$ & 0.74 & $3 \cdot 48$ & $0 \cdot 21$ & $4 \cdot 6$ \\
\hline 96 & $0 \cdot 52$ & $2 \cdot 83$ & $0 \cdot 18$ & $15 \cdot 0$ & 0.77 & $3 \cdot 36$ & 0.23 & $4 \cdot 5$ \\
\hline 120 & & & & & 0.77 & $3 \cdot 16$ & 0.24 & $5 \cdot 2$ \\
\hline
\end{tabular}

carbohydrate content could reflect, at least in part, changes in the optical properties of the organisms after the cessation of growth.

\section{Reduced state of organisms}

It is implicit in the results described above that the AME sensitivity can be markedly affected by the state of reduction of some components of the organisms at the time of test. An attempt has been made to assess the state of reduction by measuring the proportion of NAD in the reduced form in the organisms, as described by Estabrook et al. (1967). Table 5 shows the ratio of cellular NADH/NAD ${ }^{+}$and the AME sensitivity of organisms harvested from cultures grown in either YNBG or YNBG supplemented with $3 \mathrm{mg}$ sodium glutamate $\mathrm{ml}^{-1}$ and then starved and aerated. It can be seen that AME resistance increases as the ratio of $\mathrm{NADH} / \mathrm{NAD}^{+}$decreases, and that the presence of glutamate in the pool (see Fig. $1 b$ ) checks both changes. No direct correlation, such as that revealed in Fig. 3 for the rate of glutamate disappearance, is apparent in the limited data obtained.

\section{DISCUSSION}

The results described in this paper are consistent with the suggestion previously put forward (Gale et al., 1975, 1977) that the wall of $C$. albicans develops, under starvation conditions, a factor which is responsible for rendering the organism resistant to AME. This factor is reducible and the reduced form does not produce resistance. Treatment with NEM increases resistance and the enhanced resistance so produced is not decreased by reduction. The results described above, especially those in Figs 4 and 5, suggest that for organisms starved under acid conditions there are at least two factors involved in AME resistance. Treatment with ESH of organisms whose untreated s.r.c. values are less than 20 decreases the resistance to a value approximating that of growing cells. For cultures which have been starved and aerated for longer periods and for which the s.r.c. value is greater than 20, treatment with ESH does not decrease resistance to the same extent, while organisms with resistance greater than 100 are apparently unaffected by such treatment. It would appear that, as aeration and starvation continue, a second factor comes into play; this leads to high resistance which is not affected by reducing agents. The results set out in Figs 4,5 and Table 2 suggest that the reducible factor is the main cause of resistance during the early stages of starvation at $\mathrm{pH} 3$ and throughout the experimental period of 5 to $6 \mathrm{~d}$ at $\mathrm{pH} 7$. 
Cassone et al. (1979) have found marked differences in the structure and organization of the wall of $C$. albicans grown and aerated as described here and harvested at times corresponding to low, moderate and high AME resistance.

The actions of NEM and iodoacetamide (Gale et al., 1975) suggest that the reducible factor (PR) producing phenotypic resistance is a SH-compound and that oxidation or acylation of the $\mathrm{SH}$ group leads to resistance. If the level of resistance obtained after treatment with NEM can be taken as a measure of the amount of PR in the organisms treated, Fig. 6 indicates that a steady increase in PR occurs during aeration-starvation. Resistance is decreased by reduction of PR and the resistance displayed by untreated organisms in culture would therefore be determined by the degree of reduction of PR in the cells. The main sources of reducing activity in the cell appear to be utilizable carbohydrate and the action of glutamate dehydrogenases. Table 4 shows that the soluble fraction of the glucan decreases during the early stages of starvation. Table 3 and Fig. 7 show that both glutamate:NAD ${ }^{+}$ and glutamate: NADP ${ }^{+}$oxidoreductases are active in the organism and that the former remains active throughout the starvation periods used. Figure 3 shows that the resistance of untreated organisms can be correlated with the rate of disappearance of glutamate from the pool, while Table 5 shows that resistance increases as the ratio of cellular NADH/NAD ${ }^{+}$ decreases. Although it cannot be ruled out that the concentration of glutamate per se in the pool plays a role (see Fig. 2), the evidence is consistent with the hypothesis that during the early stages of starvation the AME resistance of $C$. albicans depends upon (i) the formation of a reducible factor PR in the wall and (ii) its state of reduction as a result of metabolic activities of the cell. The development of resistance can therefore be delayed by increasing the state of reduction of the organism and/or its environment.

Gale et al. (1977) noted that the presence of verrucarin or trichodermin increased the rate of development of resistance in starved organisms. They concluded that the factor PR could not be a protein but observed that the time course of $\mathrm{K}^{+}$release was different so that the trichodermin-induced resistance might be different from that in control cultures. However the work described in this paper indicates that (i) very high resistance can be due to factors other than PR and (ii) resistance in trichodermin-treated cells is not affected by NEM. The deduction that $P R$ is not a protein may not therefore be valid. At present it is not possible to say whether PR is a specific component, a complex of, or a state of linkage between, wall components.

The authors are indebted to the Medical Research Council for a grant towards the expenses of this work, and to the Wellcome Trust for help in purchasing an amino acid analyser. They also wish to thank Mr J. Bokor for his assistance in carrying out amino acid analyses, and Dr P. J. F. Henderson for carrying out the computer analyses.

\section{REFERENCES}

Cassone, A., Kerridge, D. \& Gale, E. F. (1979). Ultrastructural changes in the cell wall of Candida albicans following cessation of growth and their possible relationship to the development of polyene resistance. Journal of General Microbiology (in the Press).

Estabrook, R. W., Williamson, J. R., Frenkel, R. \& Maitra, P. K. (1967). The fluorometric determination of mitochondrial adenine and pyridine nucleotides. Methods in Enzymology 10, 474482.

FISHER, R. A. (1936). Statistical Methods for Research Workers. Edinburgh: Oliver \& Boyd.

GALE, E. F. (1974). The release of potassium ions from Candida albicans in the presence of polyene antibiotics. Journal of General Microbiology 80 , 451-465.

GALE, E. F., Johnson, A. M., Kerridge, D. \& KoH, T. Y. (1975). Factors affecting the changes in amphotericin sensitivity of Candida albicans during growth. Journal of General Microbiology 87, 20-36.

Gale, E. F., Johnson, A. M. \& Kerridge, D. (1977). The effect of aeration and metabolic inhibitors on resistance to amphotericin in starved cultures of Candida albicans. Journal of General Microbiology 99, 77-84.

Herbert, D., Phipps, P. J. \& Strange, R. E. (1971). Chemical analysis of microbial cells. Methods in Microbiology 5B, 209-344. 
Holzer, H. (1966). The control of enzyme patterns in yeast. Biochemical Journal 98, $37 \mathrm{P}$.

NorthCote, D. H. (1953). The molecular structure and shape of yeast glycogen. Biochemical Journal 53, 348-352.

Northcote, D. H. \& Horne, R. W. (1952). The chemical composition and structure of the yeast cell wall. Biochemical Journal 51, 232-236.

Nunez de Castro, I., Ugaite, M., Cano, A. \& MAYOR, F. (1970). Effect of glucose, galactose and different nitrogen sources on the activity of yeast glutamate dehydrogenase (NAD and NADPlinked) from normal strain and impaired respiration mutant. European Journal of Biochemistry 16, 567-570.

Trevelyan, W. E. \& Harrison, J. S. (1956). Studies on yeast metabolism and yeast carbohydrate fractions, separation from nucleic acids, analysis and behaviour during anaerobic fermenta tion. Biochemical Journal 63, 23-33. 